\title{
A longitudinal perspective on violence in the lives of South African children from the Birth to Twenty Plus cohort study in Johannesburg-Soweto
}

\author{
L M Richter, ${ }^{1} \mathrm{PhD}$; S Mathews, ${ }^{2} \mathrm{PhD}$; J Kagura, ${ }^{3} \mathrm{PhD}$; E Nonterah, ${ }^{1} \mathrm{MB} \mathrm{ChB}, \mathrm{MSc}$ \\ ${ }^{1}$ Department of Science and Technology-National Research Foundation Centre of Excellence in Human Development, Office of the \\ Deputy Vice-Chancellor (Research and Postgraduate Affairs), University of the Witwatersrand, Johannesburg, South Africa \\ ${ }^{2}$ Children's Institute, Faculty of Health Sciences, University of Cape Town, South Africa \\ ${ }^{3}$ Developmental Pathways to Health Research Unit, Faculty of Health Sciences, University of the Witwatersrand, Johannesburg, South Africa
}

Corresponding author: L M Richter (linda.richter@wits.ac.za)

Background. Violence against children is a significant cause of personal suffering and long-term ill health, poor psychological adjustment, and a range of social difficulties, including adverse effects intergenerationally.

Objectives. Using a large corpus of longitudinal data collected in the Birth to Twenty Plus cohort, to give an overview of exposure to and experience of violence, as well as perpetration of violence, across childhood, reported contemporaneously by several informants. This overcomes limitations of retrospectively recalled information collected from one person at one point in time.

Methods. We identified 280 data points relating to exposure to and perpetration of violence in 14 of the 21 waves of data collection from birth to 22 years of age. Data were classified into four developmental stages (preschool, primary school years, adolescence and young adulthood) and seven categories (exposure to violence in the community, home and school; exposure to peer violence; being a victim of violence, excluding sexual violence; sexual violence; and perpetration of violence). Both descriptive and inferential statistics were employed to analyse the data.

Results. Over the past two decades, only $1 \%$ of the sample had not been exposed to or experienced violence in their home, school and/or community. Two-thirds of children of schoolgoing age were reported as having been exposed to community violence, and more than half of all children to violence in their home. Reports of sexual violence increased from $10 \%$ among primary school-aged children to 30\% among adolescents and young adults. Over the course of their lives, $\sim 40 \%$ of children were reported as having been exposed to or being victims of five or six of the categories of violence coded in this analysis. High levels of violence perpetration were reported across childhood. Age and gender differences in exposure to and experience and perpetration of violence were evident, and all categories of violence were more prevalent among poorer and more disadvantaged groups.

Conclusions. Very high levels of violence were reported in all the settings of urban South African children's lives: home, community, school, among peers and in their intimate relationships. Children and youth were also reported to perpetrate high levels of violence. The personal and social costs of violence are very high, resulting in major public health problems due to its avoidable effects on short- and long-term mental and physical health and social adjustment, and intergenerationally.

S Afr Med J 2018;108(3):181-186. DOI:10.7196/SAMJ.2018.v108i3.12661

'South Africa, a country not at war, faces an unprecedented burden of morbidity and mortality arising from violence and injury.' (Seedat et al. ${ }^{[1]}$ )

Violence against children (VAC) is an abrogation of children's human rights under Section 28 of the Constitution of South Africa (SA), and under regional and international rights conventions to which SA is a signatory. It is also a significant cause of personal suffering and long-term ill health, poor psychological adjustment and a range of social difficulties, including adverse effects intergenerationally. ${ }^{[2,3]}$ While VAC is pervasive, it is largely undocumented and inadequately researched because of barriers to reporting. ${ }^{[4]}$ In acknowledgement of this, a 2014 UNICEF report on VAC is entitled Hidden in Plain Sight. ${ }^{[5]}$ A little bit is known about the tip of the iceberg of VAC serious physical, sexual or emotional abuse, usually attributed to the violent predisposition of atypical individuals, whether in or out of the family. We know much less about widespread and continuous violence in the everyday lives of children, including in SA. ${ }^{[6]}$
What we do know is that violence contributes significantly to child mortality in SA. A national mortuary-based survey found that three children a day are murdered, and that three out of four children aged $<5$ who are killed die as a result of fatal abuse by a carer at home. ${ }^{[7]}$ Data assembled by the South African Medical Research Council indicated that in $44 \%$ of sexual offences reported to the police, the victim is a child. Most rapes of children (an estimated $84 \%$ ) are perpetrated by men known to the child; in schools, the men are often teachers. ${ }^{[8]}$ Physical punishment is widely practised in SA, with nearly $60 \%$ of parents reporting that they hit their children, the majority with a belt or other object. The most common age for beatings of children is $3-4$ years ${ }^{[9]}$ Children are also exposed to various forms of emotional violence and neglect. The results of one study found that $35-45 \%$ of children had witnessed their mother being beaten, and $15 \%$ reported that one or both of their parents had been too drunk to care for them. ${ }^{[1]}$

Beyond these statistics, SA lacks systematic research into the scale and forms of violence experienced by children, limiting our ability to 
respond adequately to a significant public health problem. VAC takes several forms within a general definition, different forms of violence frequently occur together, and violence occurs in all settings in which children find themselves - at home, in school, in the community and among peers, as well as more recently in cyberspace. ${ }^{[10]}$ A 2015 national survey of 9730 young people between 15 and 17 years of age who recalled lifetime experiences of violence attempted to fill the gap. ${ }^{[11]}$ Despite methodological challenges, the study confirmed the pervasiveness of VAC, with $20 \%$ of young people reporting having experienced some form of sexual abuse in their lifetime, $30 \%$ being beaten by an adult caregiver, $16 \%$ emotional abuse and $20 \%$ feeling neglected by their parents. Based on these prevalence data, the economic cost of sexual, physical and emotional violence perpetrated against children in SA, and neglect of children - including disabilityadjusted life-years lost due to death and ill health, reduced earnings and welfare costs - is estimated as being ZAR196 billion, or $4.9 \%$ of SA's gross domestic product. ${ }^{[12]}$

\section{Objective}

Taking advantage of a large corpus of longitudinal data collected in the Birth to Twenty Plus (Bt20+) cohort, to give a perspective of exposure to and experience of violence, as well as perpetration of violence, across the time span of childhood, reported contemporaneously by several informants from infancy to young adulthood. These data overcome several limitations of retrospectively recalled information collected from one person at one point in time.

\section{Methods}

Bt20+ is a longitudinal study of children born in 1990 in the greater Johannesburg-Soweto metropolitan area, assessed on 21 occasions between pregnancy and 22 years of age. Currently, the study follows $>2000$ children and families throughout Gauteng Province. The enrolment methods, attrition and profile of the Bt $20+$ cohort are documented in detail elsewhere. ${ }^{[13]}$ On enrolment, the cohort was demographically representative of the study area, with the majority being black African and equal numbers of males and females. Bt20+ is the largest and longest-running study of child and adolescent health and development in Africa, and tracks exposures and outcomes in physical, educational, social and psychological domains. ${ }^{[13]}$ Ethical approval was obtained from the Human Research Ethics Committee of the University of the Witwatersrand, Johannesburg (ref. no. M010556).
Data collection instruments across the time span of the study were scrutinised for items relating to exposure to violence, direct experience of violence, and perpetration of violence. In 14 of the 21 waves of data collection, 280 data points relating to exposure to and perpetration of violence were identified and included in this analysis. Variables were classified into groups: mother's reports of violence during her own childhood, during her pregnancy and during the preschool years of the Bt20+ child's life; and reports of violence when children were of primary school age (6 - 13 years), adolescents (14 17 years) and young adults (18 - 22 years). Data were further classified according to whether the violence was reported by the mother, the father, the child or the child's teacher at school; whether it occurred in the home, at school, in the workplace or in the community; whether the violence was sexual; and whether it was perpetrated by peers or others. Seven categories were created: (i) exposure to violence (seeing or hearing violent episodes) in the community, (ii) at home and (iii) at school; (iv) exposure to peer violence; $(v)$ direct experience of violence (excluding sexual violence); ( $v i$ ) direct experience of sexual violence; and (vii) perpetration of violence. Some of the data were collected as part of questions on family and community wellbeing, child behavioural adjustment, etc., although in five data waves $(7,11$, 13,15 and 18 years) aspects of violence were examined as specific topics. The 280 variables, by sample size and data collection wave, are shown in Table 1.

Examples of the categories are: exposure to violence in the community (hearing gunshots), at home (seeing parents physically fighting) and at school (seeing a child beat up another); exposure to peer violence (witnessing gang violence); direct experience or being a victim of violence (mother beating the index child; being attacked at school); direct experience of sexual violence (being forced to have sex); and perpetration of violence (picking a fight, forcing someone to have sex).

Responses to items were classified as binary variables - ever or never. Multiple answers to a question (e.g. never, once or twice, a few times, many times) were collapsed into two mutually exclusive responses, 'yes' (once or twice, a few times, many times) and 'no' (never).

Both descriptive and inferential statistics were employed. Data are described using frequencies and cross-tabulations for categorical data and medians with interquartile ranges (IQRs) for skewed continuous data. Analyses were stratified according to gender, and differences were tested with Pearson's $\chi^{2}$ test, and a non-parametric two-sample Wilcoxon rank-sum (Mann-Whitney) test for skewed

Table 1. Number of variables analysed by data collection wave

\begin{tabular}{llll}
\hline Age data collected (14 waves) & Respondent & Sample size at each wave & Number of variables $(\boldsymbol{N}=\mathbf{2 8 0})$ \\
\hline Antenatal & Mother & 1595 & 4 \\
Child age 6 months & Mother & 1907 & 3 \\
4 years & Mother & 1858 & 9 \\
5 years & Mother & $625-1660$ & 13 \\
7 years & Mother and teacher & $477-2016$ & 13 \\
10 years & Child and mother & 1248 & 5 \\
11 years & Child and mother & 1794 & 22 \\
12 years & Child & 1493 & 3 \\
13 years & Child & 1647 & 16 \\
14 years & Child and mother & 2024 & 10 \\
15 years & Child & 1985 & 70 \\
16 years & Child & 1928 & 3 \\
18 years & Child, father and mother & 1993 & 101 \\
22 years & Child & 1602 & 10
\end{tabular}


data at a statistical significance level of $p<0.05$. The differences in proportion of the six classes of violence (excluding perpetration) and sociodemographic variables were examined using Pearson's $\chi^{2}$ test or Fisher's exact test where appropriate, as well as independent association of these classes of violence and sociodemographic characteristics using a univariable logistic regression analysis. Odds ratios (ORs) and 95\% confidence intervals (CIs) are reported, and $p<0.05$ is considered statistically significant.

The concentration of violence among children across time points and across types of violence was examined by creating a total violence score from six categories of violence (excluding perpetration) and expressed as quartiles due to skewness of the scores. All analyses were performed using Stata version 13 (StataCorp, USA).

\section{Results}

Characteristics of the Bt20+ sample at enrolment are shown in Table 2. The demographics of a few cases changed over the long time scale under consideration; for example, there was a small proportion of marriage and re-marriage, but this detail is not included here. There were no significant differences between boys and girls in terms of the characteristics examined.

Numbers of respondents who answered each question vary by age group, as shown in Table 3, which depicts the proportion of children reported as having been exposed to, having experienced or having perpetrated violence in the seven categories of violence indicated previously.

An overall violence score based on six categories of violence, excluding perpetration, was calculated by allocating a score of zero if the child did not report any instance of violence for any of the six categories and a score of 1 if the child reported any instance of exposure to violence in any one category across time points. A maximum score of 6 refers to exposure to all categories of violence (Fig. 1). Less than $1 \%$ of the sample had not experienced violence in any of the six categories, and $36 \%$ had experienced all six categories of violence. The violence score differed by gender $(p<0.0001)$, with a greater proportion of boys (44.4\%; 95\% CI 38.1 - 44.8) than girls (30.6\%; 95\% CI 58.3 - 64.9) reporting a score of 6.
We further determined the differences in proportions between each of the six categories of violence (excluding perpetration) and sociodemographic variables: maternal age, education and marital status, household socioeconomic status (SES), and population group. More black children reported experiencing domestic (91.4\%; $\left.\chi^{2}(3)=12.8165, p=0.005\right)$ and personal violence $\left(90.9 \% ; \chi^{2}(3)=13.3859\right.$, $p=0.004)$ than any other population group. The lower socioeconomic groups reported higher proportions of sexual violence (lowest $53.8 \%$, middle $47.6 \%$, highest $\left.38.1 \% ; \chi^{2}(2)=24.3942, p<0.0001\right)$ and peer violence (lowest $77.1 \%$, middle $70.3 \%$, highest $68.3 \% ; \chi^{2}(2)=12.0829$, $p<0.002$ ).

We further explored the independent influence of each of the sociodemographic variables on each of the six categories of violence in a univariable logistic regression analysis. Compared with black children, coloured and Indian children were 63\% (OR 0.37, 95\% CI $0.19-0.72 ; p=0.003$ ) and $78 \%$ (OR $0.22,95 \%$ CI $0.04-0.95$; $p=0.044$ ) less likely to experience domestic violence and Indian children were $94 \%$ (OR $0.06,95 \%$ CI $0.01-0.53 ; p=0.012$ ) less likely to report personal experience of violence.

The middle (OR $0.78,95 \%$ CI $0.62-0.97 ; p=0.031$ ) and highest (OR $0.53,95 \%$ CI $0.41-0.68 ; p<0.0001$ ) household SES groups were

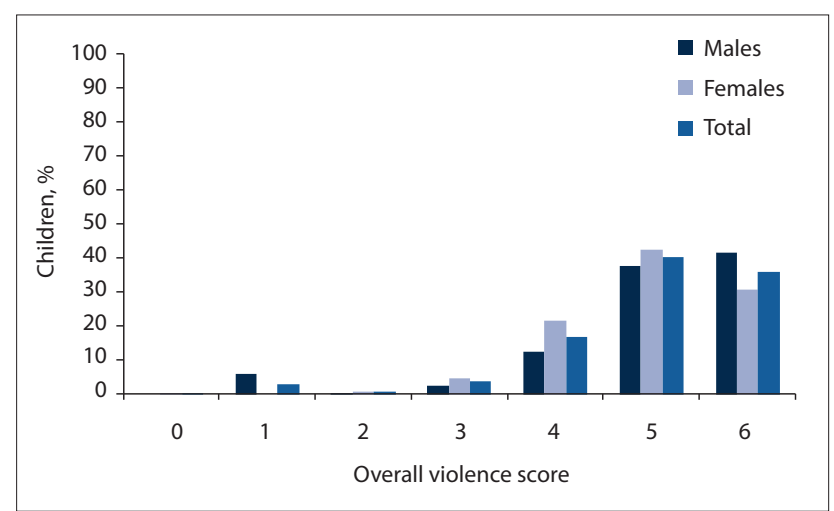

Fig. 1. Percentage of children who experienced violence according to the overall violence score ( $1-6$ across all time points) by gender.

\begin{tabular}{|c|c|c|c|}
\hline & Males $(N=1589,48.6 \%)$ & Females $(N=1681,51.4 \%)$ & Total $(N=3270)$ \\
\hline Maternal age (years), median (IQR) & $25(14-46)$ & $25(13-48)$ & $25(13-48)$ \\
\hline \multicolumn{4}{|l|}{ Population group, $n$ (\%) } \\
\hline White & $109(6.9)$ & $97(5.8)$ & $206(6.3)$ \\
\hline Black & $1245(78.4)$ & $1321(78.6)$ & $2566(78.5)$ \\
\hline Coloured & $176(11.1)$ & $207(12.3)$ & $383(11.7)$ \\
\hline Indian & $59(3.7)$ & $56(3.3)$ & $115(3.5)$ \\
\hline \multicolumn{4}{|l|}{ Marital status, $n(\%)^{*}$} \\
\hline Married & $602(38.1)$ & $597(35.8)$ & $1199(36.9)$ \\
\hline Living together & $96(6.1)$ & $117(7.0)$ & $213(6.6)$ \\
\hline Separated/divorced/widowed & $21(1.3)$ & $26(1.6)$ & $47(1.4)$ \\
\hline Single & $860(54.5)$ & $929(55.7)$ & $1789(55.1)$ \\
\hline \multicolumn{4}{|l|}{ Maternal educational status, $n(\%)^{+}$} \\
\hline No formal education & $20(1.4)$ & $27(1.8)$ & $47(1.6)$ \\
\hline Primary education & $203(14.1)$ & $204(13.7)$ & $407(13.9)$ \\
\hline Some secondary & $630(43.9)$ & $626(41.9)$ & $1256(42.9)$ \\
\hline Secondary education & $417(29.0)$ & $475(31.8)$ & $892(30.5)$ \\
\hline Post-school training & $166(11.6)$ & $161(10.8)$ & $327(11.2)$ \\
\hline Household asset score, median (IQR) & $10(0-13)$ & $10(0-13)$ & $10(0-13)$ \\
\hline
\end{tabular}




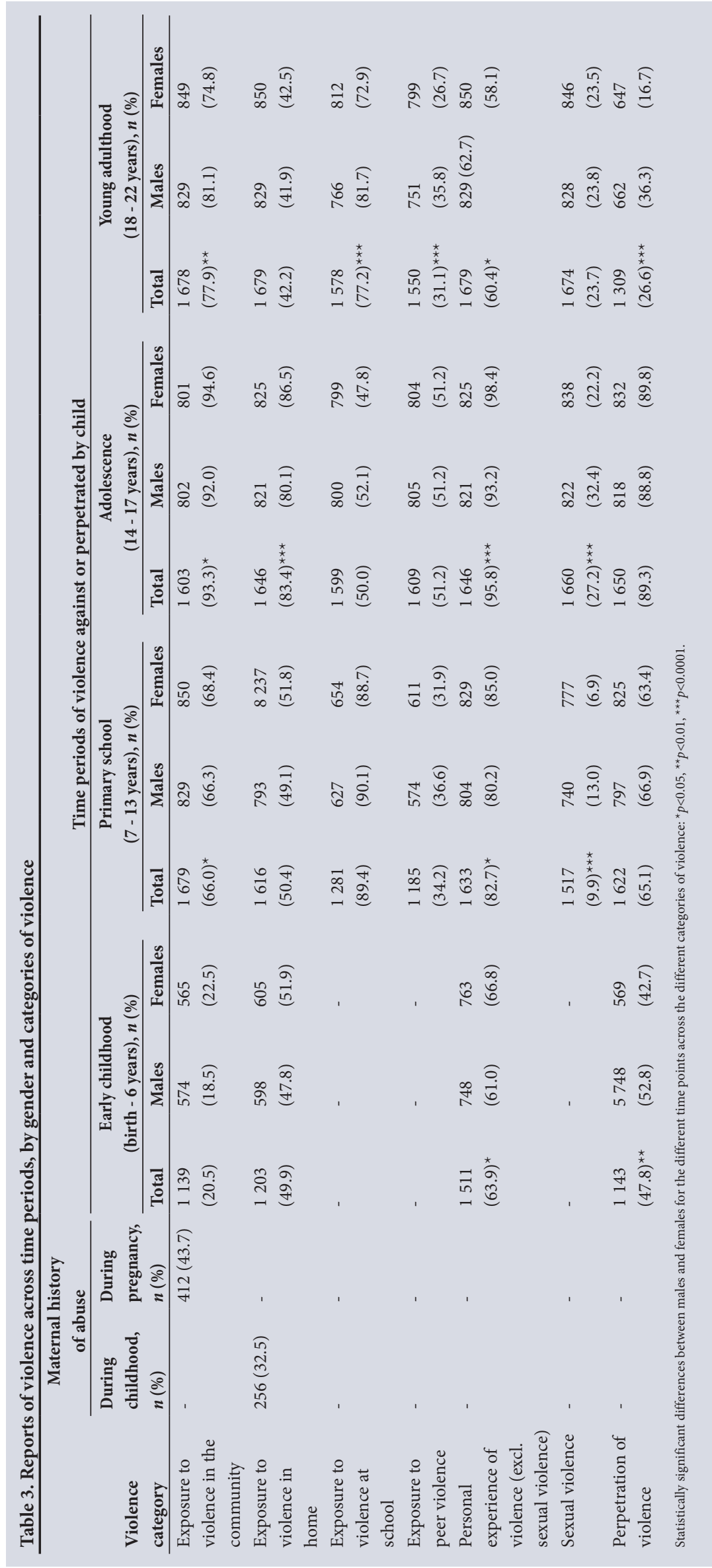

less likely to experience sexual violence compared with the lowest household SES group. They were also less likely to experience peer violence (middle OR 0.70, 95\% CI $0.54-0.90 ; p=0.006$, highest OR $0.64,95 \%$ CI $0.48-0.84 ; p=0.002$ ).

In order to examine the concentration of violence exposure and experience across time, the data were classified into quartiles, with the highest quartile (quartile 4) reporting violence across all time points by answering yes to $>75 \%$ of questions in the respective violence category; the lowest quartile answered yes to $<25 \%$ of questions in that category. As Table 4 shows, nearly half of the children (47.6\%) had intense personal experience of or exposure to violence, answering in the affirmative to $75 \%$ of questions in all categories of violence, bar sexual violence, across all time points. Forty-eight percent and $49.2 \%$ of children experienced this concentration of violence exposure in their communities and at home, respectively.

\section{Discussion}

Only $1 \%$ of this sample of children in the Soweto-Johannesburg area had been spared exposure to or experience of violence in their home, school and/or community over the past two decades. While several published and unpublished reports attest to the high levels of violence to which SA children are exposed, the extensive data reported here, over the course of childhood and across several contexts, variously reported by parents, children and teachers, document the saturation of violence in the everyday lives of children.

Two-thirds of children of schoolgoing age were reported to have been exposed to community violence, such as hearing gunshots or seeing someone attacked, the figure rising in adolescence and young adulthood. More than half of all children, increasing from childhood into adolescence, were reported to have been exposed to violence in their home. Close to half of preschool children were reported to have been victims of violence, most often through physical punishment by parents. The figure for personal experience, i.e. being a victim of violence, reached $96 \%$ among adolescents. These high rates are comparable to figures reported two decades ago in poor innercity areas in the USA, ${ }^{[14]}$ and a more recent national survey in the USA found that nearly half of American children reported being assaulted at least once in the previous year. ${ }^{[15]}$ Violence at school was reported to be experienced by about a third of primary school-aged children, the figure dropping in 
Table 4. Concentration of violence across all time for each of six categories of violence, expressed in quartiles

\begin{tabular}{llllll}
\hline & $\begin{array}{l}\text { Median time } \\
\text { points (IQR) }\end{array}$ & $\begin{array}{l}\text { Quartile 1 } \\
\text { (lowest), } \boldsymbol{n} \text { (\%) }\end{array}$ & Quartile 2, $\boldsymbol{n}$ (\%) & Quartile 3, $\boldsymbol{n}$ (\%) & $\begin{array}{l}\text { Quartile } 4 \\
\text { (highest), } \boldsymbol{n} \text { (\%) }\end{array}$ \\
\hline Exposure to violence in the community & $2(0-4)$ & 0 & $5(0.3)$ & $840(51.9)$ & $774(47.8)$ \\
$\begin{array}{l}\text { Exposure to violence in the home } \\
\text { Exposure to violence at school }\end{array}$ & $1(0-4)$ & 0 & $2(0.1)$ & $793(50.6)$ & $771(49.2)$ \\
$\begin{array}{l}\text { Exposure to peer violence } \\
\text { Personal experience of violence }\end{array}$ & $1(0-3)$ & 0 & $52(3.2)$ & $779(48.6)$ & $773(48.2)$ \\
(excluding sexual violence) & $2(0-4)$ & 0 & 0 & $466(39.3)$ & $720(60.7)$ \\
Personal experience of sexual violence & $1(0-3)$ & 0 & $5(0.3)$ & $846(52.1)$ & $774(47.6)$ \\
& & & & & \\
\end{tabular}

adolescence. Reports of sexual violence build up across childhood, from $10 \%$ among primary school-aged children to $\sim 30 \%$ among adolescents and young adults. All categories of violence were more prevalent among poorer and more disadvantaged groups.

Around $40 \%$ of children have been exposed to or experienced five or six of the categories of violence coded in this analysis over the course of their lives, i.e. they are polyvictimised, with few safe areas at home, at school, in their community, in the company of their peers or in their intimate relationships with others. Exposure to violence has severe consequences for children, including extended periods of stress, powerlessness and depression, which affect school and social adjustment. Exposed children are at risk of becoming insensitive to future violence exposures, uncaring towards others, and becoming violent themselves, ${ }^{[16]}$ although effects vary between children, including by gender. ${ }^{[17]}$ Long-term effects into adulthood of childhood exposure to violence and abuse include poor mental health, drug and alcohol abuse, risky sexual behaviour, criminality, and neglectful or abusive parenting, leading to a vicious cycle of violence and poor functionality. ${ }^{[18,19]}$

Our data indicate that SA children behave violently to others, although perpetration is not dealt with in detail here. In the preschool years, close to half of the sample were reported to be aggressive, starting fights with and bullying other children. In the primary school years, violent behaviour was reported of or by $>65 \%$ of children, rising in adolescence to $89 \%$ and declining to about a quarter in young adulthood. However, in young adulthood, perpetration was more serious than hitting others, more often taking the form of threatening someone with a gun or knife, hurting a partner, forcing someone to have sex with them, and beating up or robbing a person.

These data show that reports of violence vary across childhood, for which there are a number of possible explanations. For one, patterns and levels of violence in a society change. For example, in an earlier paper using Bt20+ data, we documented a shift from pre1994 exposure to state-sponsored political violence and politically motivated inter-ethnic violence to post-2014 exposure to criminal and family violence. ${ }^{[20]}$ Second, a developmental pattern in aggressive behaviour is commonly observed, with higher rates among very young children that decline as children mature and are socialised, ${ }^{[21]}$ although a decline was not seen among the Bt20+ sample. Except for adolescence where perpetration is equally high, violence perpetrated by males exceeds that by females, being more than double that for females by young adulthood. As has been reported in other studies, more males than females are exposed to violence in their communities, at school and with their peers.

While males typically experience more physical violence, reviews estimate a two to three times higher risk for sexual abuse among girls compared with boys. ${ }^{[22]}$ In the primary and adolescent years, we found higher rates of sexual violence against boys, although these require careful examination, as boys engage in more sexual behaviour than girls. There are, however, concerns that abuse of boys is underestimated, ${ }^{[23]}$ and specifically that current assessments of sexual abuse may not adequately capture boys' experiences of non-contact and mixed forms of abuse, and that boys under-report abuse because of fears of being labelled homosexual. ${ }^{[24]}$ Rates of reported sexual abuse of males nearly comparable to those for females have been reported from studies in sub-Saharan Africa, one using Bt20+ data. ${ }^{[11,25,26]}$

\section{Study strengths and limitations}

The strength of this analysis is that it is prospective rather than retrospective, and covers the full range of childhood and young adult years, in a variety of settings and through reports from multiple informants. An additional strength is that ongoing data are being collected on the third generation of $\mathrm{Bt} 20+$, i.e. children of the cohort, and a further round of adult data is currently being collected at a participant age of 27 years. This will enable the long-term and intergenerational effects of violence to be tracked through the study. A weakness is that the data are assembled from several different sources (self and other report, behavioural rating scales) and we did not assess the consistency of information across these sources. The number and specificity of questions about violence during the age periods also varied. It would be helpful if VAC is included in largescale longitudinal studies, such as the National Income Dynamics Study, using standard questions to ensure consistency in questions and response formats across time. While the number of white (6.3\%), coloured (11.7\%) and Indian (3.5\%) participants in the analysis prevents specific conclusions being drawn about these groups, the proportions are not markedly different from the SA population as reflected in the 2011 census $(8.9 \%, 8.9 \%$ and $2.5 \%$, respectively, with black Africans making up $79.2 \%$ of the population). ${ }^{[27]}$

\section{Conclusions}

Exposures to and experiences of violence are pervasive in the lives of SA children and young adults, at least among those living in dense urban areas such as Soweto-Johannesburg. Very high levels of violence are reported to occur in all the settings of children's lives: at home, in the community, at school, among peers and in their intimate relationships. Children and youth are also reported to be perpetrators of violence, although comparable data are not available against which to evaluate the findings. The personal and social short- and longterm costs of violence are very high, with effects into subsequent generations, yet SA does not yet have a strong focus on reducing violence and children's exposure to and experience of violence. Available evidence indicates that early intervention is needed to prevent or reduce young children's exposure to violence and other causes of toxic stress. Effective and sustainable interventions are needed to address violence as a major public health problem.

\section{Acknowledgements. None.}

Author contributions. LMR is the principal investigator of $\mathrm{Bt} 20+$ and conceptualised and wrote the first draft. SM contributed to the writing of 
the paper. JK gave oversight to the statistical analysis, and EN undertook the statistical analysis. All authors read, contributed to and approved all versions of the article.

Funding. Funding was received from the European Union (EuropeAid/134258/M/ACT/ZA PSPPD2/CfP2/2014/15/3), through the Programme to Support Pro-Poor Development in South Africa, the DST-NRF Centre of Excellence in Human Development, University of the Witwatersrand, and the Wellcome Trust (UK).

\section{Conflicts of interest. None.}

1. Seedat M, van Niekerk A, Jewkes R, Suffla S, Ratele K. Violence and injuries in South Africa: Prioritising an agenda for prevention. Lancet 2009; 374(9694):1011-1022. https://doi.org/10.1016/501406736(09)60948-x

2. Gilbert R, Widon C, Browne K, et al. Burden and consequences of child maltreatment in high-income countries. Lancet 2009;373(9657):68-81. https://doi.org/10.1016/s0140-6736(08)61706-7

3. Maniglio R. The impact of sexual abuse on health: A systematic review of reviews. Clin Psychol Rev 2009;29(7):647-657. https://doi.org/10.1016/j.cpr.2009.08.003

4. Ravi S, Ahluwalia R. What explains childhood violence? Micro correlates from VACS surveys. Psychol Health Med 2017;22(1):17-30. https://doi.org/10.1080/13548506.2017.1282162

5. United Nations Children's Fund. Hidden in Plain Sight: A Statistical Analysis of Violence Against Children. New York: UNICEF, 2014

6. Richter L, Dawes, AR. Child abuse in South Africa: Rights and wrongs. Child Abuse Rev 2008;17(2):7993. https://doi.org/10.1002/car.1004

7. Mathews S, Abrahams N, Jewkes R, Martin L, Lombard C. The epidemiology of child homicides in South Africa. Bull World Health Organ 2013;91:562-568. https://doi.org/10.2471/blt.12.117036

8. Jewkes R, Levin J, Mbananga N, Bradshaw D. Rape of girls in South Africa. Lancet 2002;359(9303):319320. https://doi.org/10.1016/s0140-6736(02)07530-x
32.

320. https://doi.org/10.1016/s0140-6736(02)07530-x
9. Dawes A, de Sa S, Kropinwnicki Z, et al. Corporal Punishment of Children: A South African National 9. Dawes A, de Sa S, Kropinwnicki Z, et al. Corporal Punishme
Survey. Cape Town: Human Sciences Research Council, 2005.

10. Aboujaoude E, Savage MW, Starcevic V, Salame, WO. Cyberbullying: Review of an old problem gone viral. J Adolesc Health 2015;57(1):10-18. https://doi.org/10.1016/j.jadohealth.2015.04.01

1. Burton P, Ward C, Artz L, Leoschut L. The Optimus Study on Child Abuse, Violence and Neglect in South Africa. Cape Town: Centre for Justice and Crime Prevention and University of Cape Town, 2015.

12. Fang X, Fry DA, Ganz G, Casey T, Ward CL. The Economic Burden of Violence Against Children in South Africa: Report to Save the Children South Africa. Georgia State University, and Universities of Cape Town and Edinburgh, 2016. https://www.savethechildren.org.za/sci-za/files/47/47ab7077-1d0d4c37-8ae2-161b18ae427a.pdf (accessed 12 February 2018).
13. Richter L, Norris S, Pettifor J, Yach D, Cameron N. Cohort profile: Mandela's children: The 1990 Birth to Twenty study in South Africa. Int J Epidemiol 2007:36(3):504-511. https://doi.org/10.1093/ije/dym016 4. Bell C, Jenkins E. Community violence and children on Chicagos's Southside. Psychiatry 1993;56(1):4653. https://doi.org/10.1080/00332747.1993.11024620

15. Finkelhor $\mathrm{D}$, Ormrod R, Turner $\mathrm{H}$, Hamby $\mathrm{S}$. The victimization of children and youth: A comprehensive, national survey. Child Maltreat 2015;10(1):5-25. https://doi.org/10.1177/1077559504271287

16. Abrahams N, Jewkes R. Effects of South African men's having witnessed abuse of their mothers during childhood on their levels of violence in adulthood. Am J Public Health 2015;95(10):1811-1816. https:// doi.org/10.2105/ajph.2003.035006

17. Evans SE, Davies C, DiLillo D. Exposure to domestic violence: A meta-analysis of child and adolescent outcomes. Aggress Violent Behav 2008;13(2):131-140. https://doi.org/10.1016/j.avb.2008.02.005

18. McDougall P, Vaillancourt T. Long-term adult outcomes of peer victimization in childhood and adolescence: Pathways to adjustment and maladjustment. Am Psychol 2015;70(4):300-310. https://doi. org/10.1037/a0039174

19. Young JC, Widom CS. Long-term effects of child abuse and neglect on emotion processing in adulthood. Child Abuse Negl 2014;38(8):1369-1381. https://doi.org/10.1016/j.chiabu.2014.03.008

20. Barbarin OA, Richter L, de Wet T, Wachtel A. Ironic trends in the transition to peace: Criminal violence supplants political violence in terrorizing South African blacks. Peace Confl 1998;4(3):283-304. https:// doi.org/10.1207/s15327949pac0403_6

21. Tremblay RE. The development of aggressive behavior during childhood: What have we learned in the past century? Int J Behav Dev 2000;24(2):129-141. https://doi.org/10.1080/016502500383232

22. Barth J, Bermetz L, Heim E, Trelle S, Tonia T. The current prevalence of child sexual abuse worldwide: A systematic review and meta-analysis. Int J Public Health 2013;58(3):469-483. http://doi.org/10.1007/ s00038-012-0426-1

23. Watkins B, Bentovim A. The sexual abuse of male children and adolescents: $A$ review of current research. J Child Psychol Psychiatry 1992;33(1):197-248. https://doi.org/10.1111/j.1469-7610.1992.tb00862.x

24. Pereda N, Guilera G, Forns M, Gomez-Benito M, et al. The international epidemiology of child sexual abuse: A continuation of Finkelhor. Child Abuse Negl 2009;33(6):331-342. https://doi.org/10.1016/j. chiabu.2008.07.007

25. Richter L, Komárek A, Desmond C, et al. Reported physical and sexual abuse in childhood and adult HIV risk behaviour in three African countries: Findings from Project Accept (HPTN-043). AIDS Behav 2014;18(2):381-389. https://doi.org/10.1007/s10461-013-0439-7

26. Richter L, Mabaso M, Ranjith J, Norris S. Early sexual debut: Voluntary or coerced? Evidence from longitudinal data in South Africa - the Birth to Twenty Plus study. S Afr Med J 2015;105(4):304-307. https://doi.org/10.7196/SAMJ.8925

27. Statistics South Africa. Census 2011. Statistical release P0301.4. Pretoria: Stats SA, 2012

Accepted 14 August 2017. 